\title{
TI.17.1
}

\section{WebISO: Target-Side Integration Models}

- PDF: 00016-WebISOTargetSidelntegrationModels.pdf

- HTML: WebISO: Target-Side Integration Models.html

More Information

\begin{tabular}{|c|c|}
\hline Repository ID & TI.17.1 \\
\hline Persistent URL & http://doi.org/10.26869/TI.17.1 \\
\hline Title & WebISO: Target-Side Integration Models \\
\hline Authors & Nathan Dors, MACE-WebISO \\
\hline Sponsor & MACE \\
\hline \multicolumn{2}{|l|}{ Review } \\
\hline Status & Legacy \\
\hline Publish Date & 10/22/2003 \\
\hline DOI & 10.26869/TI.17.1 \\
\hline \multicolumn{2}{|l|}{ Signature } \\
\hline Deprecated & No \\
\hline Future Review & $4 / 26 / 2004$ \\
\hline \multicolumn{2}{|l|}{ Supersedes } \\
\hline Format & PDF \\
\hline \multicolumn{2}{|l|}{ Related Docs } \\
\hline \multicolumn{2}{|l|}{ Development Location } \\
\hline \multicolumn{2}{|l|}{ IP Framework } \\
\hline Subject Tags & middlewarerescue \\
\hline Notes & \\
\hline
\end{tabular}

